\title{
O Diretor da Escola e o Projeto de Intervenção: dados do contexto português ${ }^{1}$ The School Director and the Intervention Project: data from the Portuguese context
}

Jorge Adelino Costa ${ }^{2}$ jcosta@ua.pt Sylvie Marinho ${ }^{3}$ sylvie.marinho@gmail.com Patrícia Castanheira ${ }^{4}$ pcastanheira@ua.pt Cidália Gonçalves ${ }^{5}$ cidalia.goncalves@ua.pt

\section{Resumo}

A partir de 2008, as escolas públicas portuguesas passaram a ter como órgão de gestão um diretor. Para candidatar-se a esse cargo é preciso apresentar um "projeto de intervenção na escola", que deverá constituir-se em um instrumento a serviço da ação estratégica do diretor. $O$ presente estudo pretende analisar o tipo de utilização que o diretor atribui a esse projeto e de que modo ele é divulgado no contexto escolar. Para alcançar esse objetivo, recorreu-se à aplicação de um inquérito por questionário com 93 diretores. Como principais conclusões, identificam-se a frágil divulgação do documento na escola e a sua pouca utilização por parte do diretor, o que parece apontar para mais um processo de formalismo técnico-burocrático, entre outros com que nos deparamos nas organizações educativas, evidenciando desconexão em discursos, intenções e ações.

Palavras-chave: Diretor da escola, Projeto de Intervenção, Projeto de escola, Liderança escolar, Portugal

\footnotetext{
${ }^{1}$ Este trabalho é financiado por Fundos FEDER, através do Programa Operacional Factores de Competitividade - COMPETE - e por Fundos Nacionais através da FCT - Fundação para a Ciência e a Tecnologia -, no âmbito do projeto "ELO - Educational Leadership Observatory/ Observatório de Liderança Educacional" (PTDC/CPE-CED/108655/2008).

${ }^{2}$ Doutor e Agregado em Ciências da Educação. Professor Catedrático do Departamento de Educação da Universidade de Aveiro, Portugal.

${ }^{3}$ Doutora em Psicologia. Bolsista de Investigação do Departamento de Educação da Universidade de Aveiro, Portugal.

${ }^{4}$ Doutora em Ciências da Educação. Investigadora do Departamento de Educação da Universidade de Aveiro, Portugal.

${ }^{5}$ Mestre em Educação. Bolsista de Investigação do Departamento de Educação da Universidade de Aveiro, Portugal.
}

Revista Educação Online, n. 15, jan./abr. 2014, p. 1-13 


\section{Abstract}

Since 2008, the management body of the Portuguese public schools is the director. The application for this post requires the presentation of a "school intervention project", which should be a tool for the strategic action of the director. This study aims at analyzing the type of use that the director makes of this project and the ways in which it is publicized in the school context. Therefore, we applied a questionnaire to 93 directors. As main conclusions, we can identify the frail knowledge of the document at the school and the little use that the director makes of it. These facts make us believe that we are before a technical-bureaucratic formal process, as many others we have in educational organizations, evidencing disconnection among discourses, intentions and actions.

Keywords: School director, School Intervention Project, School project, School leadership, Portugal

\section{Introdução}

O regime de administração e gestão das escolas portuguesas (Decreto-Lei ก.. 75/2008, de 22 de abril) introduz a figura do diretor como órgão unipessoal de gestão. Para efeitos de candidatura a esse cargo, os interessados apresentam ao Conselho Geral de cada escola um projeto de intervenção, que constitui um dos elementos de apreciação a ser levado em conta na deliberação que esse órgão de topo da estrutura escolar produzirá relativamente ao candidato a escolher para diretor.

O projeto de intervenção é um documento que deverá ter por base o projeto educativo da escola - documento que explicita "os princípios, os valores, as metas e as estratégias, segundo os quais o agrupamento de escolas ou escola não agrupada se propõe cumprir a sua função educativa" (Decreto-Lei 75/2008). Em termos concretos, o candidato deve, no projeto de intervenção, identificar os problemas, definir os objetivos e as estratégias, bem como programar as atividades que se propõe desenvolver na escola durante um mandato de quatro anos (Portaria oㅡ 604/2008, de 9 de julho).

Dessa forma, o projeto de intervenção pretende, de um modo geral, explicitar a imagem que o futuro diretor entende que a organização deverá atingir, bem como o processo para lá chegar, aproximando-se dos conceitos de visão e missão perfilhados pelos países anglo-saxônicos e considerados por diversa literatura como componentes estruturantes de uma liderança bem-sucedida (BOLMAN; DEAL, 2003; NOLAN; GODSTEIN; PFEIFFER, 1993).

Revista Educação Online, n. 15, jan./abr. 2014, p. 1-13 
É sobre a presença e divulgação desse documento no contexto escolar, bem como sobre o uso que cada diretor dele faz, que este trabalho se debruça, procurando compreender, levando em conta a percepção de 93 diretores inquiridos, algumas das facetas do projeto de intervenção e sua importância para a ação estratégica do diretor na escola.

\section{O Projeto de Intervenção do diretor}

No âmbito de vários modelos de gestão escolar, como é o caso do português, enfatiza-se a existência de um projeto de escola que enquadre e dê sentido ao desenvolvimento da ação organizacional, sendo de destacar, nesse cenário, o chamado "projeto educativo da escola".

Do mesmo modo, também o "projeto de intervenção do diretor", a que nos referimos anteriormente, pode ser percebido nesta perspectiva:

Este projeto de intervenção é um instrumento de mobilização no sentido do estabelecimento de uma visão para a escola que o candidato pretende implementar, tendo como pano de fundo as orientações fornecidas pelo projeto educativo da escola. Este projeto de intervenção deverá apresentar as áreas nas quais o candidato ao cargo de diretor entende que a escola necessita de mudança. Trata-se de uma metodologia que se encontra relacionada com a perspectiva transformacional de liderança, dado que é a visão de futuro, a missão e os objetivos definidos pelo líder que estão em destaque neste projeto. (COSTA; CASTANHEIRA; SOARES, 2012, p. 169)

Por conseguinte, poderemos equacionar essa construção de projetos na escola como procedimentos necessários ao exercício das lideranças, já que o projeto se constitui como o próprio conteúdo da liderança e, nesse sentido, a liderança sem projeto é uma liderança vazia e artificial:

Liderar uma organização implica necessariamente em saber o que se pretende para essa mesma organização, nas mais diversas facetas do seu desenvolvimento. Em termos globais, diríamos que liderar implica em ter um projeto, ainda que este assuma uma feição mais implícita e não se materialize num documento escrito. (CASTANHEIRA; COSTA, 2011, p. 125)

Ainda que se tenha de reconhecer que se trata de um procedimento recentemente introduzido, em termos de investigação, são escassos os estudos que, em Portugal, incidem sobre o projeto de intervenção do diretor, especificamente sobre o processo de

Revista Educação Online, n. 15, jan./abr. 2014, p. 1-13 
elaboração desse documento e as suas concretizações operativas. Aliás, numa revisão de literatura nacional, apenas identificamos três investigações que assumem o projeto de intervenção do diretor como objeto de estudo. Castro (2011) procedeu à análise de conteúdo de 30 projetos de intervenção dos diretores de escola recolhidos na Internet. A autora concluiu que os autores revelam um discurso predominantemente gerencialista e apresentam, como principais preocupações, a qualidade/excelência das escolas e a participação dos atores na organização. Por conseguinte, segundo a autora, o discurso dos diretores parece reproduzir o discurso político normativo, ocorrendo um processo de contaminação, apropriação e naturalização (LIMA, 2010), desconhecendo-se, no entanto, se as intenções reais e as ações desses atores estão ou não em consonância com o seu discurso. Silva (2011), num estudo de caso, procurou, entre outros tópicos, avaliar o conhecimento que os professores e outros atores tinham acerca do projeto educativo da escola e do projeto de intervenção do diretor, bem como do modo e da regularidade com que acederam a esses documentos. Conjugando a informação das diferentes fontes, a autora concluiu que ambos os documentos foram divulgados e eram do conhecimento dos diferentes atores, com a exceção dos alunos (cujo representante só conhecia o projeto educativo), e que o projeto educativo era o documento mais utilizado na escola, apesar de o diretor afirmar servir-se de ambos os projetos (projeto educativo e projeto de intervenção) conforme as situações e o âmbito das suas ações. Com objetivos similares ao estudo de Silva (2011), mas recorrendo outras fontes de informação, Castanheira e Costa (2011) administraram um questionário a 48 diretores de escolas, sensivelmente dez meses após o início dos respetivos mandatos. Os autores constataram que, de uma forma geral, a visibilidade e a possibilidade de acesso dos diversos membros da comunidade educativa e de outros interessados ao projeto de intervenção foram pouco promovidas, embora os diretores atribuíssem importância ao documento, em termos da sua utilização na orientação e vinculação da sua ação cotidiana na gestão da escola.

O presente estudo retoma os objetivos gerais desse último trabalho de investigação (CASTANHEIRA; COSTA, 2011) - procurando perceber qual a valoração que o projeto de intervenção tem para os diretores e que tipo de disseminação do

Revista Educação Online, n. 15, jan./abr. 2014, p. 1-13 
documento foi realizado no contexto escolar - com recurso a uma amostra de maior dimensão e com diretores detentores de mais tempo de mandato no cargo de responsável pela gestão da escola.

\section{Método}

\section{Amostra}

Participaram no estudo 93 diretores de escolas públicas do ensino obrigatório. Os diretores, distribuídos de forma relativamente equitativa por gênero $(51,6 \%$ homens e $48,4 \%$ mulheres), tinham em média 10 anos de experiência profissional, enquanto diretor/presidente $(M=9,72$, $D P=5,81)$, com um tempo de experiência mínimo de um mês e máximo de 25 anos. Os diretores estavam em média há três anos no mandato atual $(M=2,74, \mathrm{DP}=0,74)$, variando entre ainda não ter completado o primeiro ano e já estar no último ano de mandato. A maioria dos diretores $(81,5 \%)$ possuía habilitações específicas para o desempenho das suas funções de administração e gestão escolar, para além de terem, significativamente, mais anos de experiência no cargo $(n=75 ; M=$ $10,33, \mathrm{DP}=6,01)$ do que os diretores sem formação específica $(\mathrm{n}=14 ; \mathrm{M}=6,77$, DP $=$ $3,89), t(87)=2,165, p=, 033)$.

\section{Instrumento}

O questionário "Projeto de Intervenção na Escola" é constituído por três grupos de questões relativas: 1) à (re)formulação do projeto de intervenção; 2) à divulgação e acessibilidade do mesmo; 3) e à frequência de consulta do projeto pelo diretor desde o início do seu mandato. Os diversos itens são de resposta dicotômica, em que o diretor deve assinalar sim ou não. Excepcionalmente, o item acerca da frequência de consulta do projeto de intervenção tem cinco opções de resposta, variando entre "Nunca mais consultei o projeto", pontuada com 1, e "Consulto (praticamente) todos os dias", com 5. O questionário inclui ainda um campo "observações", em que os diretores podem escrever comentários no sentido de esclarecer as suas respostas. 


\section{Procedimentos de recolha de dados}

O questionário foi administrado no âmbito de um curso de formação em liderança educacional, ministrado em Lisboa, em 2012, a duas turmas de diretores de escolas portuguesas do ensino público. A constituição dessas turmas esteve a cargo do Ministério da Educação, e os critérios de seleção foram a manifestação de interesse por parte dos diretores das escolas portuguesas e a sua distribuição pelas várias zonas do país. No decurso de uma sessão, o formador (investigador responsável) solicitou o preenchimento do questionário, realçando o anonimato e confidencialidade dos dados recolhidos.

\section{Procedimentos estatísticos de análise de dados}

Os dados foram analisados com recurso ao software PASW Statistics 18. Para análise de associações entre variáveis categoriais, efetuou-se o teste do Qui-quadrado $\left(x^{2}\right)$, com apresentação dos resultados do teste de Fisher, quando surge uma percentagem superior a $20 \%$ de células da tabela de contingência com frequência esperada inferior a cinco (MARTINS, 2011). Para comparação entre grupos, utilizou-se o teste t-Student para amostras independentes. Quando os pressupostos subjacentes à utilização de testes paramétricos não estavam cumpridos, executou-se o teste não paramétrico equivalente (Mann-Whitney), tal como sugerido por Fife-Schaw (2006). Dado que ambos os testes (paramétrico e não paramétrico) foram concordantes, em termos de conclusões, optamos por reportar os resultados do teste paramétrico, uma vez que são mais robustos. Em todos os testes, assumiu-se como nível de significância estatística um valor de $p$ inferior ou igual a ,05. No que tange à dimensão do efeito (effect size), utilizou-se, nos testes do Qui-quadrado, o coeficiente de correlação Phi $(\phi)$ e, nos testes t-Student para amostras independentes, calculou-se, com recurso ao programa G*Power 3.1.3, o $d$ de Cohen. Para classificação da dimensão do efeito (pequeno, médio, elevado), adotaram-se os valores convencionados por Cohen (1988). 


\section{Resultados}

A maioria dos diretores escolares $(88 \%, n=81)$ afirmou ter elaborado o projeto de intervenção com base no projeto educativo da escola para a qual se candidatou. Apenas dois, dos 11 diretores que não o fizeram, justificaram a sua opção, remetendo para a inexistência do projeto educativo ou para a priorização de outros documentos, como se pode corroborar no excerto seguinte "(...) conhecia todos os anteriores projetos educativos, no entanto, não parti deles para a elaboração do meu projeto, mas dos relatórios da IGE (avaliação externa) e dos resultados de autoavaliação". Os respondentes que tiveram como base o projeto educativo da escola para definição do seu projeto de intervenção tinham mais anos de experiência profissional enquanto diretores $(n=78 ; M=10,09, D P=5,83)$, comparativamente aos que não o fizeram ( $n=$ $11 ; \mathrm{M}=6,18, \mathrm{DP}=4,09)$. Essa diferença $(\mathrm{t}(87)=2,146, \mathrm{p}=, 035)$ apresenta um tamanho de efeito elevado $(d=0,78)$.

Ao longo do mandato, apenas 11 diretores (12,6\%; resultados omissos para seis participantes) reformularam o seu projeto de intervenção e colocaram-no à apreciação

do conselho geral. A duração do mandato do diretor não está correlacionada com a reformulação do projeto de intervenção $\left(r_{p b}=, 11, p=, 328\right)$.

Vale destacar a associação existente entre a reformulação do projeto e a sua distribuição pelos docentes (teste de Fisher, $p=, 026$ ). Assim, nas dez situações (resultados omissos para uma situação) em que o projeto foi reformulado, seis diretores $(60 \%)$ tinham, antes ou depois, distribuído o projeto de intervenção pelos docentes. Quando o projeto não foi reformulado $(n=72$ ), apenas $23,6 \%$ dos diretores tinham distribuído o projeto pelos docentes. É possível que a disponibilização do projeto a outros atores da organização escolar tenha viabilizado a sua discussão aberta, propiciando a emergência de outras ideias, complementares ou antagônicas, que justificaram a redefinição do projeto, e/ou que, após a reformulação do projeto, o diretor tenha sentido a necessidade de divulgá-lo junto da comunidade docente, de modo a assegurar que as linhas orientadoras de ação fossem compreendidas e partilhadas por essa.

Revista Educação Online, n. 15, jan./abr. 2014, p. 1-13 
A visibilidade e a acessibilidade do projeto educativo foram apreciadas mediante cinco itens, referentes à localização do projeto de intervenção. A quase totalidade dos respondentes $(91,1 \%)$ afirmou que o documento se encontrava arquivado no gabinete da Direção, "à disposição de quem o solicitasse". Nesse caso, a divulgação e o acesso ao documento dependiam da atitude proativa dos interessados, abrangendo, seguramente, um público mais reduzido e restrito. Contrariamente, o projeto de intervenção estava menos visível e/ou acessível, nos dois locais com maior probabilidade de difusão entre os diversos membros internos e externos à escola, designadamente o website da escola $(48,4 \%)$ e as paredes/murais da escola $(10,2 \%)$. De igual modo, apenas $27,1 \%$ dos diretores assumiram a prática de distribuir o projeto de intervenção pelos docentes da escola. De forma mais expressiva, 60,7\% dos diretores assinalaram que o projeto de intervenção se encontrava integrado em vários dossiers de estruturas orgânicas da Escola. O gráfico $1^{6}$ representa as respostas positivas pelas diferentes dimensões.

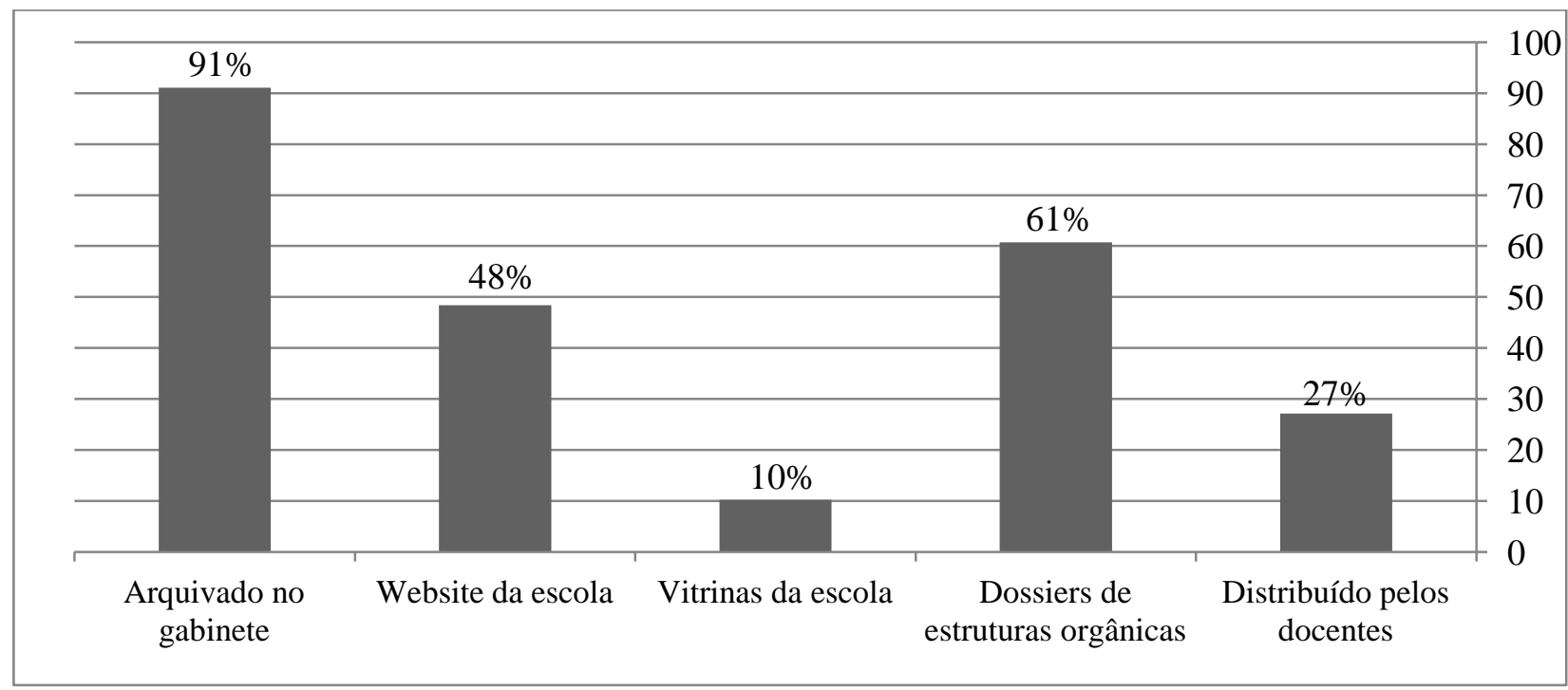

Gráfico 1. Distribuição da localização do projeto de intervenção

\footnotetext{
${ }^{6}$ Aonde se lê "vitrinas", entenda-se murais. Nota da revisão.
} 
A opção pelo website $\left(x^{2}(1)=9,33, p=, 002\right)$ e por murais da escola (teste de Fisher, $p=, 003)$, enquanto formas de divulgação do projeto de intervenção, está associada com o gênero, com um tamanho de efeito médio $(\phi=0,32$ e $\phi=0,33$, respetivamente). Dessa forma, mais homens do que mulheres divulgaram o projeto de intervenção através do website (33\% homens vs. 15,4\% mulheres) e de expositores na escola $(10,2 \%$ homens vs. $0 \%$ mulheres).

Se considerarmos as quatro formas em que o projeto de intervenção é ativamente divulgado (site da escola, afixado na escola, distribuído a todos os docentes e integrado em dossiers de estruturas orgânicas), observa-se uma média de 1,40 ( $\mathrm{DP}=0,95)$, indicando que os diretores apenas difundiram o projeto num dos dois locais. De acordo com a distribuição, $17,2 \%$ dos diretores $(n=16)$ não difundiram o projeto de nenhuma dessas formas, 40,9\% ( $n=38)$ divulgaram em apenas um local, $26,9 \%(n=25)$ em dois locais e $15,1 \%(n=14)$ em três locais.

Em termos de organização pessoal, 40,7\% dos diretores tinham o projeto em cima da sua mesa, facilitando o seu acesso imediato. Destaque-se a associação entre a presença do projeto na mesa do diretor e a habilitações para o cargo $\left(x^{2}(1)=6,47, p=\right.$ ,011), com um tamanho do efeito baixo $(\phi=0,27)$. Dessa forma, registra-se uma maior tendência para os diretores com habilitações específicas a terem o projeto de intervenção em cima da mesa, comparativamente aos diretores sem habilitações $(47,1 \%$ vs. $12,5 \%)$. Por outro lado, também se observa uma associação entre a presença do projeto na mesa do diretor e a sua ausência nos vários dossiers de estruturas orgânicas da escola $\left(x^{2}(1)=5,06, p=, 024\right)$. Assim, quando o projeto de intervenção está em cima da mesa do diretor (40\% dos casos), esse documento está mais frequentemente ausente dos dossiers $(22,4 \%)$ do que presente $(17,6 \%)$.

O projeto de intervenção constitui (teoricamente) o instrumento orientador da ação do diretor escolar; contudo $3,2 \%(n=3)$ mencionaram nunca o ter consultado, $13,5 \%(n$ = 12) consultaram-no no máximo três vezes, e a maioria $(69,9 \% ; n=65)$ consultou-o entre quatro e dez vezes. Somente um décimo dos diretores referiu consultar o projeto de intervenção semanalmente $(6,5 \%)$ ou quase diariamente $(3,2 \%)$. É importante frisar

Revista Educação Online, n. 15, jan./abr. 2014, p. 1-13 
que o tempo de mandato não está correlacionado de forma significativa com a periodicidade de consulta do projeto. Aliás, $80 \%$ dos diretores que exercem o cargo há três anos ou mais afirmaram que, ao longo de todo o mandato, consultaram de quatro a dez vezes o seu projeto de intervenção. Por outro lado, a frequência da consulta ao projeto de intervenção pelo diretor escolar difere significativamente, em função da sua acessibilidade ao website da escola $(t(85)=3,220, p=, 002 ; d=0,70)$, em expositores da escola $(t(82)=2,639, p=, 010 ; d=0,84)$ e em dossiers de estruturas orgânicas da escola $(t(83)=1,994, p=, 049 ; d=0,45)$. Os diretores consultaram mais frequentemente o projeto de intervenção, quando esse estava presente nesses três locais ( $M_{\text {website }}=3,20, D P=0,68 ; M_{\text {expositor }}=3,44, D P=0,73 ; M_{\text {dossier }}=3,08, D P=0,68$ ) do que quando não estava presente $\left(M_{\text {website }}=2,76, D P=0,57 ; M_{\text {expositor }}=2,88, D P=\right.$ 0,$\left.59 ; M_{\text {dossier }}=2,79, \mathrm{DP}=0,60\right)$.

\section{Conclusões}

Tal como esperado, a maioria dos diretores, principalmente aqueles que têm mais anos de experiência profissional nesse tipo de cargo, consultaram o projeto educativo da escola quando da elaboração do seu projeto de intervenção. É natural que os diretores reconheçam a importância do projeto educativo da escola enquanto eixo norteador e estejam cientes da necessidade de o discurso orientador da sua ação estar em consonância com esse documento. Porém, não se pode deixar de realçar que 11 dos 93 respondentes afirmem não ter consultado aquele documento. Essa situação, minoritária mas relevante, denota desconexão organizacional em termos de construção de uma estratégia de desenvolvimento da escola, desvaloriza o documento institucional de topo da organização escolar (o projeto educativo da escola) e se aproxima das leituras mais críticas sobre a construção de projetos, que apontam para a inconsequência, para o ritual e para a ficção (COSTA, 2003).

Também apenas $12,6 \%$ dos diretores alteraram o seu projeto de intervenção e o colocaram novamente à apreciação do conselho geral da escola. Ainda que não se trate de uma imposição ou indicação da legislação em vigor, a reformulação pode ser percebida como positiva, pois implica adaptações e adequações às necessidades, em

Revista Educação Online, n. 15, jan./abr. 2014, p. 1-13 
constante mutação, da escola, numa lógica de melhoria. Aliás, essa porcentagem é inferior à obtida no estudo efetuado anteriormente sobre o mesmo assunto (CASTANHEIRA; COSTA, 2011), em que $20,8 \%$ dos diretores alteraram o projeto. Ou seja, esperar-se-ia que, com projetos de intervenção há mais tempo em vigor, existisse maior propensão para a sua reformulação. Dessa forma, os dados podem indicar que o projeto de intervenção do diretor se constitui como mais "um formalismo técnicoburocrático, cujos efeitos terminam no momento da obrigatoriedade legal da sua apresentação em função dos procedimentos formais inerentes ao respectivo/concurso eleição para o cargo" (CASTANHEIRA; COSTA, 2011, p. 132). Porém, também é possível que o diretor tenha efetuado alterações (residuais ou substanciais) no seu projeto de intervenção e não o tenha submetido à nova apreciação.

No que diz respeito à divulgação e disponibilização pública do projeto de intervenção, essas parecem ser pouco promovidas, comprometendo, dessa forma, parte da utilidade prática do instrumento. De uma forma geral, é reconhecido o arquivamento do projeto em dossiers (61\%), e subvalorizada a sua distribuição pelos docentes $(27 \%)$ e a exposição na escola (10\%). Esses resultados são similares aos obtidos no estudo de Castanheira e Costa (2011), apesar de se destacar negativamente a menor exposição do projeto de intervenção em locais de visibilidade no espaço físico da escola (10\% vs. $26,1 \%)$. Nesse sentido, poderíamos inferir que os diretores não valorizam a importância do projeto de intervenção, quer para a mobilização e envolvimento dos atores, quer para a assunção de uma liderança participativa e distribuída comprometida com desígnios estratégicos comuns.

A maioria dos diretores $(69,9 \%)$ afirmou consultar o seu projeto de intervenção entre quatro e dez vezes ao longo do seu mandato. Esse cenário aplica-se a $80 \%$ dos diretores que exercem o cargo há três anos ou mais, remetendo para uma consulta anual a trimestral. Essa esporadicidade poderá corroborar a hipótese supramencionada, do projeto de intervenção enquanto um formalismo técnicoburocrático, em que os discursos nem sempre se traduzem em práticas consequentes por parte dos diretores (CASTRO, 2011). Porém, também se poderá equacionar a hipótese de o diretor conhecer em detalhe as intenções, ações, objetivos e estratégias

Revista Educação Online, n. 15, jan./abr. 2014, p. 1-13 
firmados no projeto de intervenção, dispensando a sua consulta para colocá-los em prática.

Retomando o pressuposto de que a gestão organizacional exige um projeto que Ihe conceda sentido estratégico e que suporte o desenvolvimento do seu quadro de referência em termos de liderança (COSTA; FIGUEIREDO, 2013), entendemos que o projeto de intervenção do diretor, presente nas escolas portuguesas, poderá contribuir, se articulado com o projeto educativo, para processos de desenvolvimento organizacional da escola. Contudo, os resultados deste estudo não são animadores relativamente a esse desiderato: a articulação débil entre o projeto de intervenção e o projeto educativo, a não assunção de uma linha de ação esclarecedora e envolvente dos diversos atores organizacionais, a discrepância entre a produção do documento e a sua esperada prática de consulta e revisão, geram ambiguidades sobre o efeito real que o projeto de intervenção do diretor assume na escola.

\section{Referências bibliográficas}

BOLMAN, L.; DEAL, T. Reframing organizations: artistry, choice and leadership. San Francisco, CA: Jossey-Bass, 2003.

CASTANHEIRA, P.; COSTA, J. O projecto de intervenção do director: onde anda e para que serve? In. NETO-MENDES, A.; COSTA, J. A. ; VENTURA, A. (Eds.). A emergência do diretor da escola: questões políticas e organizacionais. Atas do VI Simpósio sobre Organização e Gestão Escolar. Aveiro: Universidade de Aveiro, 2011. p. 125-134.

CASTRO, D. Os projetos de intervenção dos diretores de escola: Uma construção discursiva a partir das regulações do discurso político-normativo. In. Sensos, v. 1, n. 2, p. 9-28, 2011.

COHEN, J. Statistical power analysis for the behavioural sciences. New York: Academic Press, 1988.

COSTA, J. A. Projectos educativos das escolas: um contributo para a sua (des)construção. In. Revista Educação e Sociedade, v. 24, no 85, p. 1319-1340, 2003.

; FIGUEIREDO, S. Quadros de referência para o desempenho dos líderes escolares. In. Ensaio: Avaliação e Políticas Públicas em Educação, v. 21, n. 79, p. 183202, 2013.

; SOARES, S.; CASTANHEIRA, P. Liderança escolar, projeto e trabalho em equipa: explorando cruzamentos concetuais. In. Cadernos de Pesquisa: Pensamento Educacional, v. 7, n. 17, p. 164-178, 2012.

Revista Educação Online, n. 15, jan./abr. 2014, p. 1-13 
FIFE-SCHAW, C. Levels of measurement. In. BREAKWELL, G. M.; HAMMOND, S.; FIFE-SCHAW, C.; SMITH, J. A. (Eds.). Research methods in psychology. London, England: Sage, 2006. p. 50-63.

LIMA, L. Concepções de escola: para uma hermenêutica organizacional. In:

(Org.). Perspectivas de análise organizacional das escolas. Vila Nova de Gaia: Fundação Manuel Leão, 2010. p. 15-57.

MARTINS, C. Manual de análise de dados quantitativos com recurso ao IBM SPSS: saber decidir, fazer, interpretar e redigir. Braga: Psiquilíbrios, 2011.

NOLAN, T.; GOODSTEIN, L.; PFEIFFER, J. W. Plan or die! 10 keys to organizational success. San Diego, CA: Pfeiffer \& Company, 1993.

PORTUGAL. Decreto-Lei n. 75/2008, de 22 de abril. Regime de autonomia, administração e gestão das escolas. In. Diário da República, Lisboa, n. 79, I Série, 22 de abr. 2008.

Portaria n. 604/2008, de 9 de julho. Regras a observar no procedimento concursal prévio à eleição do diretor, nos termos do Decreto-Lei n. 75, de 22 de abril de 2008). In. Diário da República, Lisboa, n. 131. I Série, 9 de jul. 2008.

SILVA, A. P. Projeto de intervenção do diretor versus projeto educativo da escola. Aveiro, 2011. Dissertação (Mestrado em Ciências da Educação) - Departamento de Educação, Universidade de Aveiro. Aveiro, 2011.

Revista Educação Online, n. 15, jan./abr. 2014, p. 1-13 